\title{
Age-dependent deficits in fear learning in heterozygous BDNF knock-out mice
}

\author{
Thomas Endres ${ }^{1}$ and Volkmar Lessmann \\ Institute of Physiology, Medical Faculty, Otto-von-Guericke-University Magdeburg, 39120 Magdeburg, Germany
}

\begin{abstract}
Beyond its trophic function, the neurotrophin BDNF (brain-derived neurotrophic factor) is well known to crucially mediate synaptic plasticity and memory formation. Whereas recent studies suggested that acute BDNF/TrkB signaling regulates amygdala-dependent fear learning, no impairments of cued fear learning were reported in heterozygous BDNF knockout mice $\left(\mathrm{BDNF}^{+/-}\right)$. Since brain BDNF levels are known to decline with aging, we hypothesized that $\mathrm{BDNF}^{+/-}$mice might show reduced fear learning at older ages. Indeed, $\mathrm{BDNF}^{+/-}$animals revealed an age-dependent deficit in fear learning 3 mo after birth and beyond. Since there were no alterations between the two genotypes during the conditioning training and when testing short-term memory, this learning deficit most likely reflects a deficit in memory consolidation. Importantly, there were no differences in spontaneous motor behavior and baseline anxiety in $\mathrm{BDNF}^{+/-}$animals at any age tested. Following behavioral testing quantification of BDNF levels in the basolateral amygdala with a sensitive BDNF ELISA revealed a positive correlation between the levels of BDNF in the amygdala and the individual learning performance. However, the age-dependent decline in the efficiency of fear conditioning in $\mathrm{BDNF}^{+/-}$mice was not accompanied by reduced BDNF expression in the amygdala. Thus, while reduced BDNF levels in general correlate with less efficient fear learning, this lack of BDNF can be compensated in young but not in older animals, suggesting that the cellular mechanisms responsible for fear learning consolidation become BDNF-dependent 3 mo after birth.
\end{abstract}

Fear learning is a simple but highly adaptive learning process that increases the survival probability of an individual in potentially threatening situations (e.g., Maren 2001). The ability of fear learning is widely distributed in the animal kingdom and highly conserved throughout evolution (Pape and Pare 2010). Since dysfunctions of fear learning and fear memory extinction are believed to be one of the major causes of phobias and anxiety disorders, like post-traumatic stress disorders (e.g., Koenigs and Grafman 2009; Jovanovic and Ressler 2010; Mahan and Ressler 2012), unrevealing the underlying mechanisms of these learning processes might lead to new insights and potential treatment strategies for these diseases.

In classical (i.e., Pavlovian) fear conditioning a distinct neutral cue like a light or a tone stimulus is paired with an aversive unconditioned stimulus (US, e.g., a weak electric foot shock). After one or several pairings of these two stimuli, the previously neutral stimulus becomes a conditioned stimulus (CS) that afterward can alone induce fear similar to the US (for review, see Fendt and Fanselow 1999; LeDoux 2000). The key brain structure mediating this cued fear learning in the rodent as well as in the human brain is the amygdala (for review, see e.g., LeDoux 2007; Ehrlich et al. 2009; Pape and Pare 2010).

The neurotrophin BDNF (brain-derived neurotrophic factor) is not only important for neuronal survival and differentiation in the developing brain, but it is also a crucial mediator for the induction and maintenance of synaptic plasticity (e.g., long-term potentiation), thereby modulating learning processes (see e.g., Lessmann et al. 2003; Bekinschtein et al. 2008; Gottmann et al. 2009; Cowansage et al. 2010; Yoshii and Constantine-Paton 2010; Meis et al. 2012). It was demonstrated recently that BDNF

\footnotetext{
${ }^{1}$ Corresponding author

E-mail thomas.endres@med.ovgu.de

Article is online at http://www.learnmem.org/cgi/doi/10.1101/Im.028068.112.
}

signaling is also involved in cued fear learning. Fear learning induces a strong increase in BDNF mRNA expression within the basolateral amygdala (BLA). Likewise, when BDNF signaling is impaired in the BLA by overexpression of a nonfunctional, truncated TrkB-receptor (tTrkB), fear learning is impaired (Rattiner et al. 2004a,b, 2005; Jones et al. 2007). In a more recent study, Ou and colleagues demonstrated that fear learning induced a strong expression of BDNF protein in the BLA at two distinct time windows during the consolidation process (Ou et al. 2010). Depending on the time point of interference, acute inhibition of BDNF/TrkB signaling by application of k252a or TrkB-IgGs into the BLA either completely blocked the generation of fear memory (infusion 30 min before training), or prevented the formation of a long-term memory (infusion $9 \mathrm{~h}$ after training) (Ou et al. 2010). Correspondingly, fear learning can be improved by stimulation of TrkB receptors by systemic application of the BDNF mimetic 7,8-Dihydroxyflavone (Andero et al. 2010). In conclusion, these studies clearly demonstrate an important role for BDNF/TrkB-signaling in amygdala-dependent cued fear learning, especially in the consolidation process of these memories.

In contrast, most studies using genetic approaches to alter BDNF expression in mice report no deficits in cued fear learning. For example, animals that carry a point mutation in the BDNF gene ( $\mathrm{Val} / \mathrm{Met}$ or Met/Met), which is known to affect BDNF secretion (Egan et al. 2003), showed intact cued fear learning (Chen et al. 2006; Soliman et al. 2010). Results of studies using inducible BDNF-KO mouse lines are quite diverse: Inducible $\mathrm{KO}$ animals with forebrain-restricted decreased BDNF levels (including the BLA) revealed impaired cued fear learning when KO induction started before birth, but not if $\mathrm{KO}$ induction started in adult animals (Monteggia et al. 2004). In contrast, another very early inducible forebrain-specific BDNF-KO mouse has been shown to possess intact cued fear learning (Gorski et al. 2003). However, these findings obtained in inducible forebrain-specific BDNF-KO mice might not be finally conclusive, since in these animals 
only the BLA was affected. As it has also been shown that other parts of the amygdala, like the central amygdala, are crucially involved in the acquisition of fear memories (e.g., Ciocchi et al. 2010) the unaltered BDNF-levels in these areas might still be sufficient to ensure proper fear learning. Heterozygous BDNF-knockout $\left(\mathrm{BDNF}^{+/-}\right)$mice circumvent this issue but have been consistently reported to show intact cued fear learning (Chourbaji et al. 2004; Liu et al. 2004; Chen et al. 2006; Karpova et al. 2011). Unfortunately, homozygous BDNF-knock-out mice cannot be used for behavioral experiments, since these animals die within the first 3 wk after birth (Ernfors et al. 1994; Korte et al. 1995). The heterozygous animals express $\sim 50 \%-60 \%$ BDNF-protein compared with wild-type littermates (Kolbeck et al. 1999; Chourbaji et al. 2004; Genoud et al. 2004; Abidin et al. 2006; Boger et al. 2011). Thus, the remaining BDNF levels in the amygdala of these animals might still be sufficient to ensure cued fear learning. Of note, the studies testing cued fear learning in $\mathrm{BDNF}^{+/-}$mice so far used either only females (Chourbaji et al. 2004), rather strong conditioning procedures (Karpova et al. 2011), or young adult (i.e., 2-mo-old) animals (Liu et al. 2004; Chen et al. 2006), and these parameters are likely to have critically influenced the results in the fear-conditioning experiments. Interestingly, BDNF and TrkB receptor protein levels change with development (Kolbeck et al. 1999) and during aging (Croll et al. 1998; Katoh-Semba et al. 1998; Karege et al. 2002; Silhol et al. 2005; von Bohlen und Halbach 2010; Boger et al. 2011), and these changes seem to be regulated differentially in distinct brain areas. For example, the BDNF content in the hypothalamus of Sprague-Dawley rats starts to decrease 2 mo after birth, whereas BDNF levels in the hippocampus of these animals remain unchanged between 1 and 22 mo of age (Silhol et al. 2005). Thus, it seems reasonable to assume that a similar age-dependent decline of BDNF protein levels also occurs in $\mathrm{BDNF}^{+/-}$mice. Provided there is also an age-dependent decline of BDNF protein in the amygdala, older $\mathrm{BDNF}^{+/-}$mice might show impairments in cued fear learning, when the BDNF content falls below a critical threshold that is required to assure proper fear learning. Therefore, we tested $\mathrm{BDNF}^{+/-}$mice and their corresponding wild-type littermates for their performance in cued fear learning at different ages. Since $\mathrm{BDNF}^{+/-}$mice are known to show a faster increase in body weight than wild-type animals (Lyons et al. 1999; Kernie et al. 2000; Boger et al. 2011), we also tested the spontaneous motor activity of the animals using an open-field paradigm. Furthermore, using the elevated plus maze test, we also analyzed whether anxiety behavior changes with the increasing age of the animals. In parallel to the behavioral experiments, we quantified the amount of BDNF protein in the BLA of some of the tested animals, using the ELISA technique, in order to see (1) whether there is a general correlation between the amount of BDNF protein in the amygdala and the individual fear-learning performance and (2) whether there is a decline of BDNF protein levels in the amygdala during aging that leads to an impaired fear learning.

Our results show that there is a learning deficit in cued fear learning in $\mathrm{BDNF}^{+/-}$mice when they are 3 mo of age or above. Furthermore, we observed a positive correlation between BDNF levels in the amygdala and the individual fear learning abilities.

\section{Results}

\section{Open field}

In order to analyze whether the $\mathrm{BDNF}^{+/-}$mice show any alterations in basal motor activity or anxiety behavior we first performed an open-field test (Fig. 1A,B). An ANOVA using geno- type, age, as well as the interaction of both between-subject factors revealed that $\mathrm{BDNF}^{+/-}$mice did not show any changes in spontaneous motor activity compared with wild-type mice at any test age (Fig. 1A) in all quantified activity-related behaviors (traveled distance, average speed, and number of line crossings: genotype: $F^{\prime} s \leq 0.90, P^{\prime} s \geq 0.33$; genotype $\times$ age: $F^{\prime} s \leq 0.16, P^{\prime} s \geq$ $0.98)$. Interestingly, all of these quantified behaviors varied between the different age groups and slightly increased with aging (factor age: $F^{\prime} \mathrm{s} \geq 3.00, P^{\prime} \mathrm{s} \leq 0.015$ ). To test the baseline anxiety of the animals we compared the time the animal spent in the center of the arena with the time they spent in the peripheral zone (Fig. 1B). An ANOVA using the factors age, genotype, and zone (periphery vs. center) revealed no significant general effects of the factors age and genotype $\left(F^{\prime} \mathrm{s}<0.0001, P^{\prime} \mathrm{s}=1\right)$, whereas there is a significant effect of the factor zone $\left(F_{(1,77)}=2780.8, P \leq\right.$ $0.0001)$, indicating that the animals generally spent less time in the central zone than in the peripheral zone. In addition, the ANOVA revealed a significant interaction of these three factors (age $\times$ genotype $\times$ zone: $F_{(5,77)}=2.71, P=0.02$ ), but post-hoc Tukey comparisons revealed only significant differences between the time all groups spent in the two zones, whereas there were no significant differences between the two genotypes at any tested age. Also, the traveled distance in the center as well as the number of entries in the center area did not differ between the two genotypes (genotype: $F^{\prime} \mathrm{s} \leq 0.49, P^{\prime} \mathrm{s} \geq 0.49$, genotype $\times$ age: $F^{\prime} \mathrm{s} \leq$ $0.50, P^{\prime} \mathrm{s} \geq 0.78$ ). Post-hoc Tukey comparisons revealed no significant differences between the two genotypes in all quantified behaviors at any tested age. In conclusion, these data indicate no altered anxiety behavior in $\mathrm{BDNF}^{+/-}$mice.

\section{Elevated plus maze}

To analyze the basal anxiety behavior of these animals in more detail, we performed an elevated plus maze test with the same animals. Also here we observed no differences in the anxiety levels between the two genotypes at any tested age, since we observed no differences in the time the animals spent on the open arm (Fig. 1C, genotype: $F_{(1,77)}=1.74, P=0.19$; age: $F_{(5,77)}=0.43, P=$ 0.82 ; age $\times$ genotype: $F_{(5,77)}=0.63, P=0.68$ ), closed arm (genotype: $F_{(1,77)}=0.22, P=0.64$; age: $F_{(5,77)}=1.38, P=0.24$; age $\times$ genotype: $\left.F_{(5,77)}=1.22, P=0.31\right)$ or in the center of the elevated plus maze (genotype: $F_{(1,77)}=0.20, P=0.65$; age: $F_{(5,77)}=1.46$, $P=0.21$; age $\times$ genotype: $\left.F_{(5,77)}=0.27, P=0.93\right)$. Interestingly, the number of risk assessment episodes (Fig. 1D, factor age: $F_{(5,77)}=6.45, P<0.0001$ ) and head dips (data not shown, age: $\left.F_{(5,77)}=4.68, P=0.0009\right)$ increased with the age of the tested animals, but both behaviors were not influenced by the genotype of the animals (genotype: $F^{\prime} s \leq 0.61, P^{\prime} s \geq 0.43$; genotype $\times$ age: $\left.F^{\prime} \mathrm{s} \leq 1.21, P^{\prime} \mathrm{s} \geq 0.31\right)$. Post-hoc Tukey comparisons revealed no differences between $\mathrm{BDNF}^{+/-}$and WT mice in all of these quantified behaviors at any tested age.

\section{Acquisition of fear memory}

\section{Fear conditioning}

In these experiments the same animals were used that had been analyzed in the open field and elevated plus maze. To test whether $\mathrm{BDNF}^{+/-}$mice show a deficit in the acquisition of amygdaladependent fear memories, we analyzed the behavior of the animals during the fear-conditioning training. First, we analyzed the overall freezing behavior expressed throughout the whole conditioning session by calculating an overall ANOVA (data not shown): No differences were observed between the two genotypes $\left(F_{(1,2487)}=0.83, P=0.36\right)$. However, the ANOVA revealed significant effects for the factor age $\left(F_{(5,2487)}=32.4, P<0.0001\right)$ as well as for the interaction of these two factors (age $\times$ genotype: 

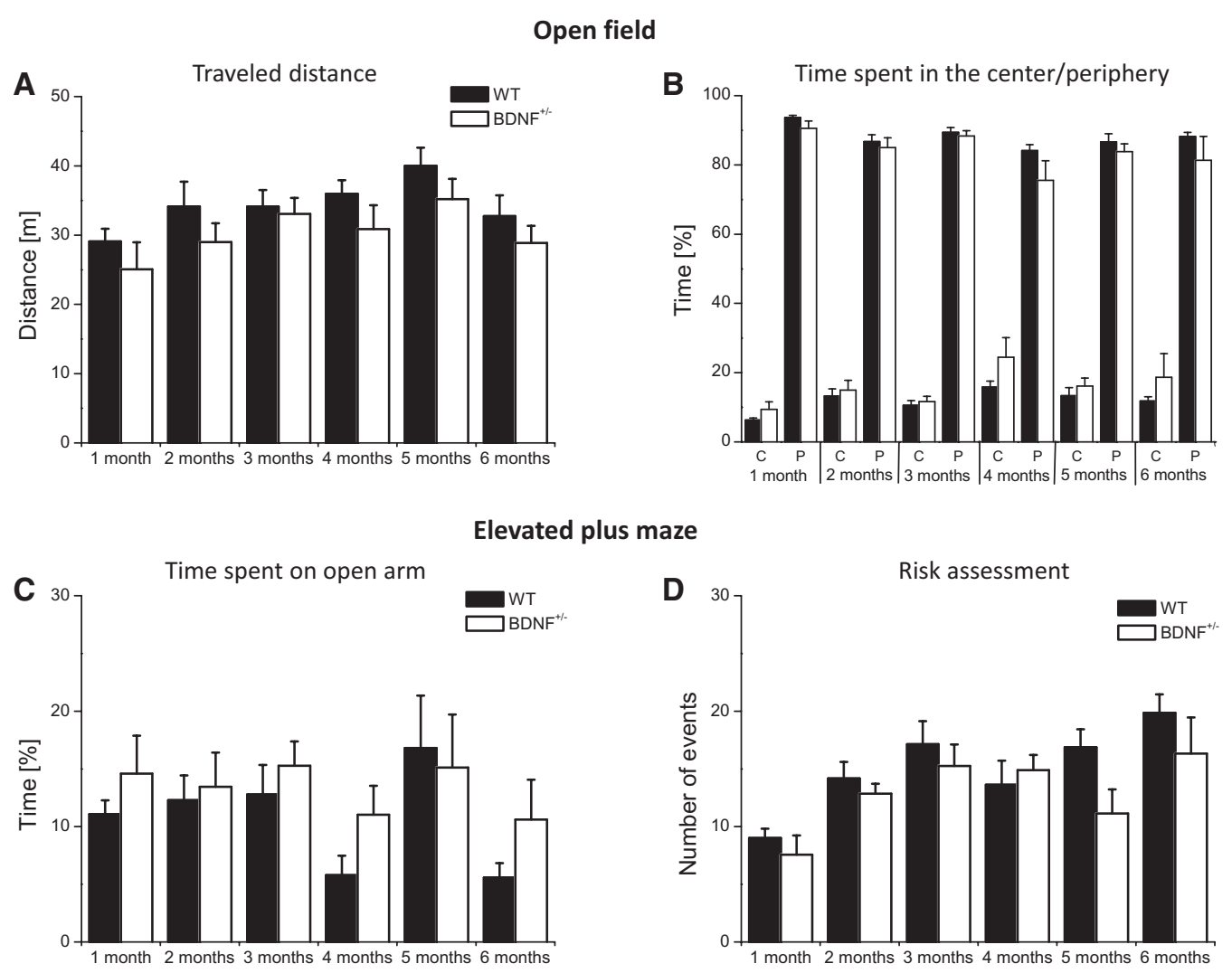

Figure 1. Spontaneous motor activity and anxiety levels are not changed in $\mathrm{BDNF}^{+/-}$mice. Mean (+SEM) of behavioral responses of BDNF ${ }^{+/-}$and wild-type mice tested in the open field $(A, B)$ and the elevated plus maze $(C, D)$. The spontaneous motor activity was not changed between the two genotypes at any tested age $(A)$. Also, baseline anxiety was not altered by the genotype at any tested age, as there were no differences in the time the animals spent in the center (C) or periphery $(P)$ of the open-field arena $(B)$, or on the open arm of the elevated plus maze $(C)$, as well as in the number of risk assessment behavior $(D)$.

$\left.F_{(5,2487)}=3.25, P=0.006\right)$. But post-hoc Tukey comparisons revealed no significant differences between same-aged genotypes, except for 5-mo-old animals. Taken together, these results indicate that there were no general alterations in freezing behavior expressed in response to the tone-shock pairings by the two genotypes. The number of jumps during the conditioning trial was in general very low (means $<1$ ) and did not differ between the two genotypes at any tested age $\left(P^{\prime} \mathrm{s}>0.3\right)$, suggesting no altered pain sensitivity in response to the used foot-shock intensity.

To get more insight into the acquisition of fear memories, we took a closer look at the freezing expressed during the tone presentations in the conditioning training (CS1-CS3) (Fig. 2A). Here an ANOVA revealed significant effects of the factors phase $\left(\mathrm{CS} 1-\mathrm{CS} 3: F_{(2,321)}=72.13, P<0.0001\right)$ and age $\left(F_{(5,321)}=\right.$ $8.72, P<0.0001)$, but neither significant effects for the factor genotype $\left(F_{(1,321)}=0.004, P=0.95\right)$ nor for the interaction of these three factors (phase $\times$ age $\times$ genotype: $F_{(10,321)}=1.24, P=$ 0.26). Post-hoc Tukey comparisons revealed significant increments in freezing behavior between CS1 and CS3 in all tested age groups, but no significant differences between the two genotypes within each age group. In conclusion, these results suggest that there is no impairment in the acquisition of fear memories in $\mathrm{BDNF}^{+/-}$mice at any tested age.

\section{Short-term memory}

Since the freezing behavior expressed during the conditioning training is controlled by several factors that are not all related to learning processes such as, e.g., post-shock freezing, we decided additionally to test the acquisition of fear memory in the $\mathrm{BDNF}^{+/-}$ mice in a more indirect way by assessing the short-term memory performance of the animals. Therefore, we exposed 6-mo-old animals to the CS $20 \mathrm{~min}$ after the conditioning training had taken place. Under these conditions we observed no differences between the two genotypes in freezing behavior in response to the CS (Fig. $2 \mathrm{~B}$, post-hoc Tukey comparisons, ANOVA: phase: $F_{(1,119)}=22.7$, $P<0.0001$, genotype $\times$ phase: $\left.F_{(1,119)}=1.5, P=0.23\right)$. These results further suggest that the acquisition of fear memories in $\mathrm{BNDF}^{+/-}$mice is still intact, even in 6-mo-old animals.

\section{Fear memory retrieval}

To test the fear memory of the animals, we exposed the animals $24 \mathrm{~h}$ after conditioning to the CS in a different context. The results of this experiment are depicted in Figure 3, A and B. To analyze the fear-learning abilities of the animals we compared the freezing behavior expressed during the CS presentation with freezing during the habituation period and during a time window 30 sec before the CS presentation (pre-CS), respectively. Therefore, we calculated an overall ANOVA using the factors age (1-6 mo), genotype (WT vs. $\mathrm{BDNF}^{+/-}$) and phase (habituation, pre-CS, CS), as well as the interaction of these factors. This comparison revealed general effects on freezing behavior by the phase $\left(F_{(2,338)}=152.83, P<\right.$ $0.0001)$ as well as by the age $\left(F_{(5,338)}=5.77, P<0.0001\right)$, but no general effect of the genotype $\left(F_{(1,338)}=0.05 ; P=0.83\right)$. Most importantly, there was a significant interaction of these three 


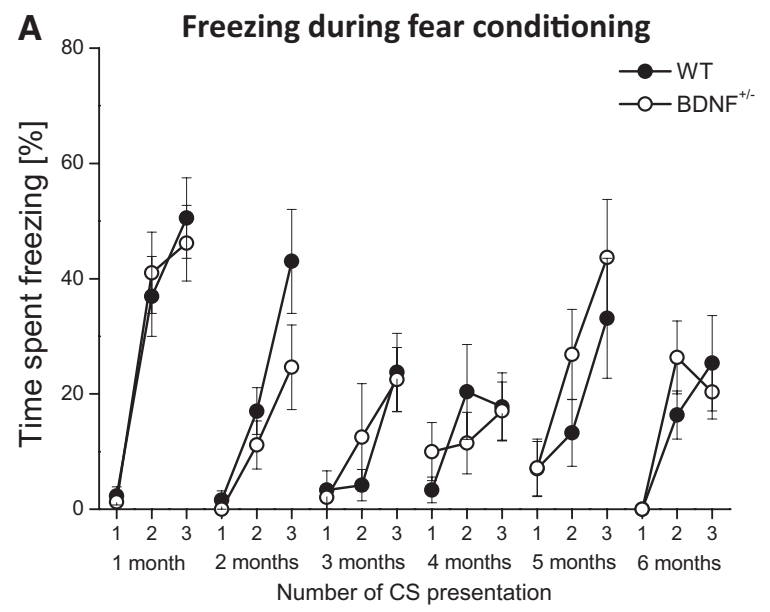

B

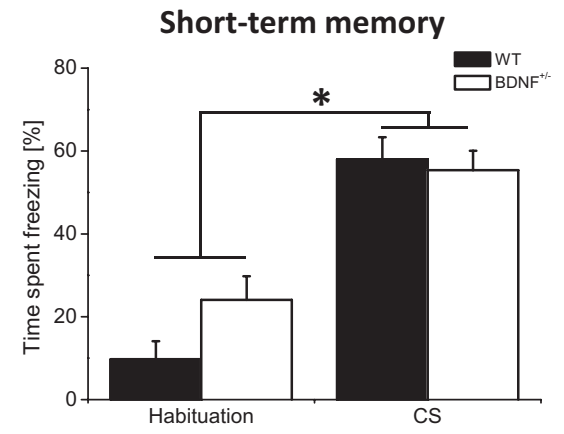

Figure 2. Acquisition of fear memories is not altered in 6-mo-old $\mathrm{BDNF}^{+/-}$mice. $(A)$ Freezing behavior expressed in response to the CS during the fear-conditioning training. Here we observed no differences between $\mathrm{BDNF}^{+/-}$and wild-type mice, suggesting no impairment in acquisition of fear memories in $\mathrm{BDNF}^{+}$mice (mean $\pm \mathrm{SEM}$ ). (B) Six-month-old animals were exposed to the CS $20 \mathrm{~min}$ after the fearconditioning training took place in order to test their short-term memory. Here we observed no differences between the $\mathrm{BDNF}^{+/-}$mice and their wild-type littermates (mean + SEM, $\left[{ }^{*}\right] P<0.05$ ).

factors (age $\times$ genotype $\times$ phase: $\left.F_{(10,338)}=5.14, P<0.0001\right)$, indicating that the extent of freezing behavior expressed in response to the CS changes during the aging process, and this was furthermore influenced by the genotype of the animals (cf. Fig. 3A).

Post-hoc Tukey comparisons revealed no significant differences in freezing behavior expressed during the habituation as well as during the pre-CS phase between the two genotypes at any tested age, indicating no general increased baseline freezing in $\mathrm{BDNF}^{+/-}$mice. Most important, $\mathrm{BDNF}^{+/-}$mice between 3 and 6 mo of age showed significantly less freezing in response to the CS as their age-matched WT littermates. Furthermore, $\mathrm{BDNF}^{+/-}$mice of these ages showed no significant difference between pre-CS and CS freezing, indicating no specific increase in freezing in response to the $\mathrm{CS}$ in $\mathrm{BDNF}^{+/-}$mice of the respective age. In addition, 5- and 6-mo-old $\mathrm{BDNF}^{+/-}$mice also showed no difference between CS freezing and the amount of freezing expressed during the habituation period.

Since it seems like there is a tendency in $\mathrm{BDNF}^{+/-}$mice to express more baseline freezing, we additionally analyzed the total freezing behavior between the CS presentations. Here an ANOVA revealed a significant general effect of the genotype $\left(F_{(11,107)}=7.73, P=0.006\right)$, but neither a significant general effect of the age $\left(F_{(5,107)}=1.03, P=0.40\right)$ nor of the interaction of these two factors $\left(F_{(5,107)}=1.32, P=0.26\right)$. A post-hoc Tukey comparison revealed no significant difference at any tested age between the two genotypes, indicating no general increased baseline freezing in $\mathrm{BDNF}^{+/-}$mice.

For clarity of presentation, we subtracted the freezing behavior expressed during the pre-CS phase from the freezing behavior expressed during the CS presentation, resulting in a $\Delta$ Freezing score (Fig. $3 \mathrm{~B}$ ). This $\Delta$ Freezing score was also used later to compare the individual learning abilities with the BDNF protein levels in the amygdala of the respective animal (Fig. 4B).

To ensure that the observed learning deficit in older $\mathrm{BDNF}^{+/-}$mice is not attributable to sensory deficits, we performed a control experiment in which we exposed the animals to a stronger fear-conditioning protocol (i.e., six CS-US-pairings). Since we expect the strongest impairment in 6-mo-old animals, we performed this experiment with animals of that age group. Under these conditions we observed that $\mathrm{BDNF}^{+/-}$-animals responded with a similar level of conditioned freezing to the CS as the wild-type littermates (Fig. 3C, phase: $F_{(1,89)}=91,9, P<$ 0.0001 , genotype: $F_{(1,89)}=3.01, P=0.086$, phase $\times$ genotype $\left.F_{(1,89)}=2.97, P=0.088\right)$. Post-hoc Tukey comparisons revealed a significant increase in freezing in response to the CS in both groups, but no differences in freezing behavior between the groups either during the habituation or during the CS presentations.

Since the observed learning deficit in $\mathrm{BDNF}^{+/-}$mice could be rescued by applying a stronger fear-conditioning protocol (i.e., more CS-US pairings), we also tested whether a weaker fearconditioning procedure (i.e., one CS-US pairing) reveals a learning deficit in younger (i.e., 2-mo-old) $\mathrm{BDNF}^{+/-}$mice that showed intact fear learning in response to our standard protocol (i.e., three CS-US pairings) (Fig. 3C). Here an ANOVA revealed a significant effect of the factor phase $\left(F_{(1,19)}=34.77, P<0.0001\right)$ but neither a significant effect of the genotype $\left(F_{(1,19)}=1.73, P=\right.$ 0.21 ) nor a significant interaction of these two factors (phase $x$ genotype: $\left.F_{(1,19)}=0.69, P=0.42\right)$, indicating that both genotypes learned the task equally well. Post-hoc Tukey comparisons revealed significant increased freezing to the CS in both genotypes, but no differences in freezing behavior between the two genotypes, either during the habituation or during the CS periods. In conclusion, these results show that a weaker fear-conditioning protocol is not able to induce a learning deficit in 2-mo-old $\mathrm{BDNF}^{+/-}$mice.

\section{BDNF quantification of amygdala tissue}

To elucidate whether the observed learning deficit in 3-mo-old animals is accompanied by a decline in BDNF protein in the BLA, we excised the BLA of some of the tested animals and quantified the amount of BDNF protein using the ELISA technique. To get sufficient group sizes ( $n=8$ per group) we pooled the data of 1- and 2-, 3- and 4-, as well as 5- and 6-mo-old animals, respectively (Fig. 4A). An ANOVA revealed a significant effect of the genotype $\left(F_{(1,46)}=63,26, P<0.001\right)$, indicating a significantly reduced amount of BDNF protein in $\mathrm{BDNF}^{+/-}$mice to $46.7 \%$ in 1 - to $2-, 54.2 \%$ in 3 - to 4 -, and $55.9 \%$ in 5 - to 6 -moold animals. However, we did not observe any significant alterations in the amount of BDNF protein with aging for a given genotype (age: $F_{(2,46)}=0.31, P=0.74$; genotype $\times$ age $F_{(2,46)}=0.54$, $P=0.58$ ). Post-hoc Tukey-comparisons revealed significant differences in the BDNF protein content in the BLA between wildtype and $\mathrm{BDNF}^{+/-}$mice in all age groups, but no significant differences between the different age groups within each genotype. In conclusion, these results reveal that the observed learning deficit in older mice is not accompanied by a decline of BDNF protein levels in the BLA.

Finally, we analyzed whether the individual learning performance of the animals correlated with the amount of BDNF protein expression in the BLA (Fig. 4B). Here we observed a positive 
A

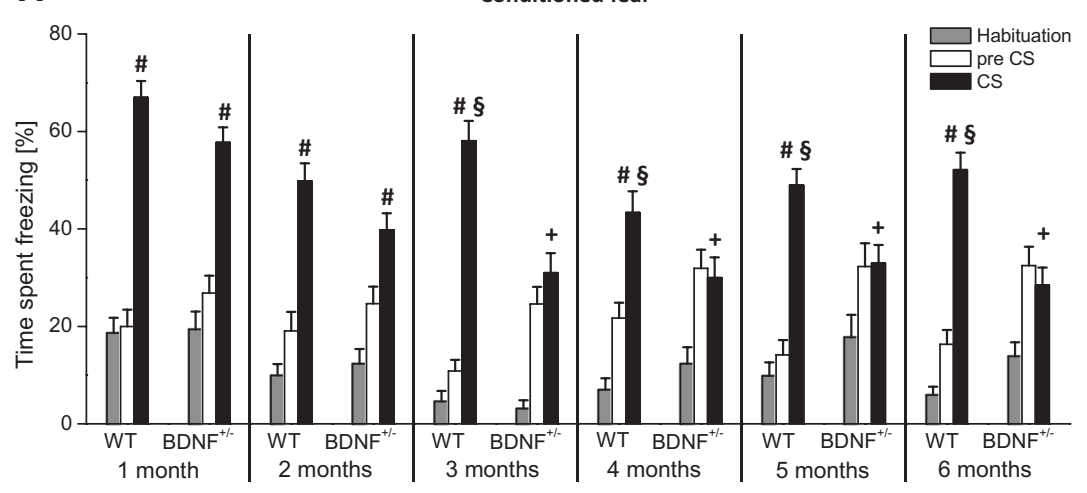

B

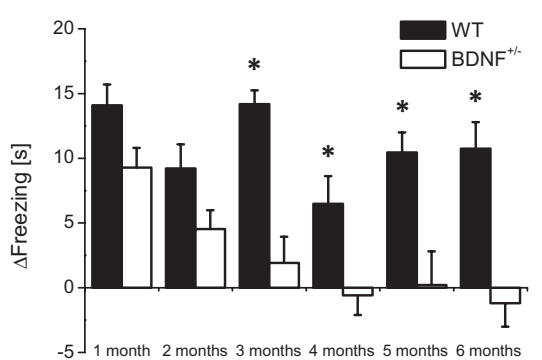

C Different number of CS-US pairings

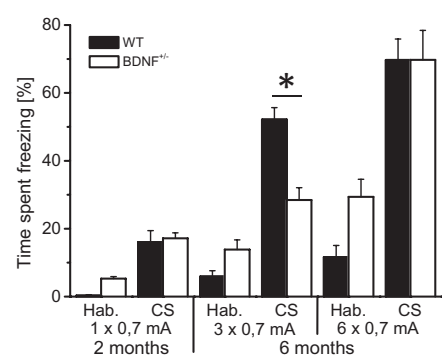

Figure 3. Fear-learning performance of $\mathrm{BDNF}^{+/-}$mice and wild-type littermates at different ages. $(A)$ Freezing behavior expressed during the habituation, $30 \mathrm{sec}$ before the CS (pre-CS) and during the 30-sec CS presentation (means $+\mathrm{SEM}$ ). $\mathrm{BDNF}^{+/-}$mice showed a strong impairment of fear learning when they were $3 \mathrm{mo}$ or older at the time of testing. (\#) A significant difference of the CS freezing to the habituation and pre-CS; $(+)$ a significant difference between CS and habituation; (§) a significant difference between wild-type and $\mathrm{BDNF}^{+/-}$mice. All statistics were calculated by ANOVA, followed by post-hoc Tukey comparisons. (B) To get a learning score that is independent of the baseline freezing, we subtracted the freezing the animal expressed during the pre-CS phase from the freezing the animal expressed during the CS presentation (= $\Delta$ Freezing; $\left[{ }^{*}\right] P<0.05$, post-hoc Tukey comparisons). (C) Increasing the number of CS-US pairings during the conditioning training overcomes the learning deficit in 6-mo-old $\mathrm{BDNF}^{+/-}$mice. In contrast, younger $\mathrm{BDNF}^{+/-}$mice showed no learning deficit if the number of CS-US-pairings was decreased (mean + SEM, $\left[^{*}\right] P<0.05$ ).

correlation between the amount of BDNF protein in the BLA and the fear-learning performance in WT mice $(r=0.51)$, but not in $\mathrm{BDNF}^{+/-}$mice $(r=0.014)$.

Since we expected a positive correlation between these factors only in animals that successfully learned the task (i.e., $\Delta$ Freezing $\geq 5 \mathrm{sec}$ ), we performed a second analysis in which we separated the analysis into a learner and a nonlearner group, irrespective of the age and genotype of the animals (Fig. 4C). Here we observed a positive correlation between the BDNF content in the BLA and the fear-learning abilities in the learner group $(r=0.74)$, whereas we observed no such correlation in animals that didn't learn the task $(r=0.09)$. In conclusion, these results demonstrate that the individual fear-learning performance relies on the amount of BDNF protein in the BLA.

\section{Discussion}

In the present study, we show for the first time that heterozygous BDNF knock-out mice exhibit a deficit in amygdala-dependent cued fear learning. This learning deficit occurs in an agedependent manner when the animals reach an age of at least $3 \mathrm{mo}$, while other behavioral properties like agility or anxiety remained unchanged between the two genotypes for all tested age groups. To test whether this impaired fear learning was accompanied by a reduction of BDNF within the BLA, we quantified the BDNF content of fear-conditioned animals of both genotypes and observed a positive correlation between the individual fear-learning performance and the amount of BDNF protein in the amygdala.

In contrast to previous studies analyzing cued fear learning in $\mathrm{BDNF}^{+/-}$ mice (Chourbaji et al. 2004; Liu et al. 2004; Chen et al. 2006; Karpova et al. 2011) we observed a deficit in cued fear learning in these mice. However, our results are not contradictory to the abovementioned studies; thus, Liu et al. (2004) as well as Chen et al. (2006) observed intact fear learning in 2-mo-old $\mathrm{BDNF}^{+/-}$ mice similar to what we observed in our animals. Karpova et al. (2011) observed no impaired fear learning in 3-mo-old $\mathrm{BDNF}^{+/-}$mice, but they applied a stronger fear-conditioning protocol (i.e., increased number of CS-US pairings). Similarly, we also observed a rescue of fear learning in even older (i.e., 6-moold) $\mathrm{BDNF}^{+/-}$mice, when increasing the number of CS-US pairings (see below). In the study of Chourbaji et al. (2004) only 5-mo-old female mice were used. Since several recent studies using $\mathrm{BDNF}^{+/-}$mice or other transgenic mouse lines with altered BDNF expression demonstrated sex-dependent alterations on behavioral as well as on cellular levels in these animals (e.g., Ren-Patterson et al. 2006; Monteggia et al. 2007; Autry et al. 2009; Hill and van den Buuse 2011; Papaleo et al. 2011; Wu et al.2012), results obtained from experiments exclusively performed with either males or females might not be directly comparable with respect to BDNF-mediated effects. In conclusion, our results are in line with previous studies using similar aged male animals and similar fear-conditioning procedures (i.e., identical number of CSUS-pairings), but stress the importance of age-dependent changes in fear learning in $\mathrm{BDNF}^{+/-}$mice.

When the $\mathrm{BDNF}^{+/-}$mice are 3 mo of age or above, a learning deficit in fear learning occurs. In several recent studies it has been shown that fear learning differs between adolescent and adult mice, with 4-wk-old mice expressing more conditioned freezing and showing more generalized fear than 2-mo-old animals (Hefner and Holmes 2007; Ito et al. 2009).

Since activity-dependent synaptic plasticity in the amygdala underlies the acquisition of fear memory (cf., e.g., McKernan and Shinnick-Gallagher 1997; Rogan et al. 1997; Johansen et al. 2011), it is of note that the fear-learning-related mechanisms of synaptic plasticity also change with the age of mice. Thus, a loss of longterm potentiation induced by a spike-timing-dependent plasticity paradigm at the thalamic input in 2-mo-old mice has been reported, suggesting a shift of importance of synaptic plasticity, underlying memory formation, toward the cortical input during development (Pan et al. 2009). However, this developmental change in synaptic plasticity cannot directly explain the observed learning deficit in $\mathrm{BDNF}^{+/-}$mice, since the learning deficit should then already be present in 2-mo-old animals. Interestingly, the number of amygdala projection neurons, e.g., from the BLA to the prefrontal cortex, strongly increases during the first $90 \mathrm{~d}$ of development (Cunningham et al. 2002, 2008), also 

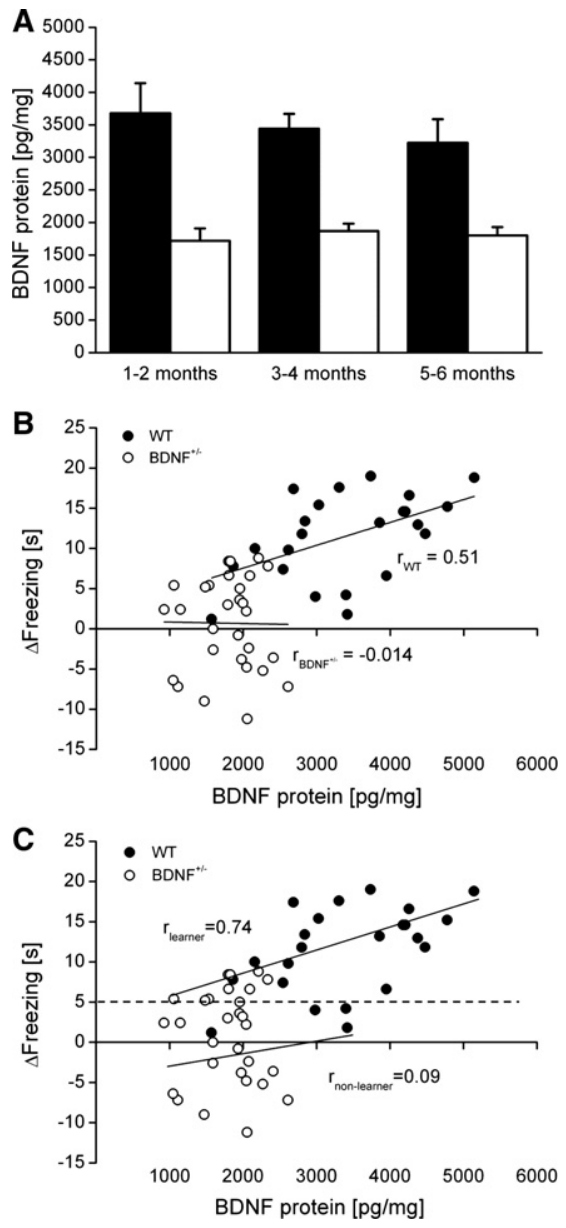

Figure 4. Quantification of BDNF protein levels in the basolateral amygdala. (A) Total BDNF protein levels of 1- to 2-, 3- to 4-, and 5- to 6-mo-old $\mathrm{BDNF}^{+1-}$ mice and wild-type littermates. $\mathrm{BDNF}^{+/-}$mice show $\sim 50 \%$ of the BDNF levels of their wild-type littermates. We observed no changes in BDNF levels within each genotype during the first 6 mo of development. $(B)$ Correlation between the individual fear-learning performance and the respective BDNF level in the BLA of the same animal. In wild-type animals (indicated as solid circles), we observed a positive correlation of the BDNF levels to the learning success $(r=0.51)$, whereas we observed no such a correlation in $\mathrm{BDNF}^{+/}$animals $(r=0.014)$ (indicated as open circles). (C) Since we expected a positive correlation between amygdalar BDNF protein and fear-learning performance only in animals that successfully learned the task, we divided the animals into a learner (i.e., $\Delta$ Freezing $>5 \mathrm{sec}$ ) and a no-learner group, irrespective of the genotype. Here we observed a positive correlation of BDNF protein and fear-learning performance in the learner group $(r=0.74)$, whereas we observed no such correlation in animals that did not learn the task $(r=0.09)$.

suggesting that morphological alterations in amygdala networks appear during the adolescent period of the animals. It remains to be determined whether the age-dependent learning deficit we observe in $\mathrm{BDNF}^{+/-}$mice can be explained by a switch of learning-related synaptic plasticity from a circuit showing BDNF-independent plasticity, to a different synaptic circuit (at $3 \mathrm{mo}$ ) that shows BDNF-dependence of synaptic plasticity.

In order to gain more insight into the observed learning deficit, we analyzed the freezing behavior of the animals during the conditioning trial. Here, we observed that there was no difference between the two genotypes in the increase in freezing behavior between the first and the third tone presentation during the conditioning training (cf. Fig. 2A), stressing that the acqui- sition of fear memory is not impaired in $\mathrm{BDNF}^{+/-}$mice. To further evaluate the acquisition of fear memories and to get rid of potential interfering effects of post-shock freezing, we performed a control experiment in which we tested conditioned fear behavior $20 \mathrm{~min}$ after conditioning training. Since we expected the most pronounced learning deficit in 6-mo-old animals, we performed this experiment only with $\mathrm{BDNF}^{+/-}$and WT mice of this age. This experiment did not reveal any differences in freezing in response to the CS between the two genotypes, suggesting that the acquisition of fear memory should still be intact, since otherwise there should have been an obvious deficit in the shortterm memory. Interestingly, a study using transgenic mice with distinct point mutations in the TrkB receptor showed impaired acquisition of fear memory, specifically when the PLC $\gamma$-site of TrkB receptors was mutated (Musumeci et al. 2009). Likewise, when the BDNF signaling is acutely blocked in the amygdala during the conditioning training by administration of the Trk inhibitor k252a or using TrkB-IgGs (that scavenge endogenously released $\mathrm{BDNF}$ ), the acquisition of fear memories was blocked (Ou and Gean 2006). These previous studies suggest that BDNF signaling within the BLA is required for the acquisition of fear memory. But in these studies the BDNF signaling was completely blocked during the conditioning training, whereas in our study the $\mathrm{BDNF}^{+/-}$mice possess only a reduced amount of BDNF. Thus, our results suggest that the remaining levels of BDNF in the BLA of older $\mathrm{BDNF}^{+/-}$mice are still sufficient to mediate the acquisition of fear memory, whereas these levels seem to be insufficient to consolidate this fear memory and transfer it into a long-term memory. In accordance with this consideration, Ou and colleagues (Ou and Gean 2006; Ou et al. 2010) showed that BDNF protein levels in the amygdala increases at two distinct time windows during the memory consolidation process (i.e., around 1 and $12 \mathrm{~h}$ after conditioning, respectively), and that interfering with BDNF transmission at these time points leads to an impaired memory consolidation. Thus, BDNF seems to be crucially involved in transferring fear memory into long-term memory.

By analyzing the BDNF protein concentration in the amygdala of the tested animals, we could verify that $\mathrm{BDNF}^{+/-}$mice possess $\sim 45 \%-60 \%$ of BDNF compared with wild-type littermates. This is in accordance with previously described levels of $\mathrm{BDNF}$ in other brain structures of $\mathrm{BDNF}^{+/-}$mice (see, e.g., Kolbeck et al. 1999; Abidin et al. 2006; Boger et al. 2011). When comparing the individual BDNF concentration in the amygdala with the individual learning abilities, we observed a general positive correlation of these two factors in wild-type animals, such that increased BDNF in the amygdala positively correlates with a better learning performance of an individual animal. This positive correlation was even more prominent when we restricted the analysis to animals that reached a critical threshold of learned fear (i.e., "learners," with a $\Delta$ Freezing $>5 \mathrm{sec}$ ). To our knowledge, these results are the first to prove a positive correlation between amygdala-dependent fear learning and BDNF levels in the amygdala. However, similar positive correlations between BDNF protein levels in distinct brain areas and cognitive abilities have also been described recently for other learning tasks in rats (Francia et al. 2006; Barichello et al. 2010; Hopkins and Bucci 2010), and a positive correlation between BDNF blood plasma concentration and cognitive performance has also been reported (for reviews, see, e.g., von Bohlen und Halbach 2010; Erickson et al. 2011). Interestingly, with aging the expression of BDNF declines in a large number of brain structures as well as in the blood serum of humans and animals (e.g., Croll et al. 1998; KatohSemba et al. 1998; Silhol et al. 2005; von Bohlen und Halbach 2010; Boger et al. 2011; Erickson et al. 2011). Compared with the just-mentioned studies which also analyzed quite old animals 
(i.e., 12-24 mo), we analyzed only 1- to 6-mo-old animals. During this early phase of aging we didn't observe a decline in BDNF content in wild-type animals. Only in 6-mo-old animals did we observe a first tendency for a beginning decline in BDNF protein (data not shown). Surprisingly, there were no changes in BDNF levels in the amygdala of $\mathrm{BDNF}^{+/-}$mice during the critical time window (around 3 mo of age), when the learning deficit becomes apparent. In addition, we did not observe any correlation between the individual fear-learning abilities and the $\mathrm{BDNF}$ content in the BLA of $\mathrm{BDNF}^{+/-}$mice. This suggests that-in addition to BDNF-other factors that co-regulate fear learning and which might have compensated the BDNF deficit in young animals decline with age, thus causing the learning deficit in older animals. Alternatively, the process of synaptic plasticity that underlies fear learning might switch from BDNFindependent pathways to BDNF-sensitive circuits (compare discussion above).

Several substances like, e.g., Zn ions (Hwang et al. 2005), Cu ions (Hwang et al. 2007), dopamine (Swift et al. 2011), or adenosine (see, e.g., Tebano et al. 2010) have been reported recently to transactivate Trk receptors. It thus seems possible that one or several of these transactivating factors of the TrkB-receptor undergo a decline during early post-puberty development in $\mathrm{BDNF}^{+/-}$mice, thus causing the observed learning deficit in older $\mathrm{BDNF}^{+/-}$mice. A possible influence of these factors on our observed age-dependent learning deficit in $\mathrm{BDNF}^{+/-}$mice remains to be determined.

It has been shown recently that interfering with the processing of proBDNF to mature BDNF during the consolidation of hippocampus-dependent contextual fear memory results in an impaired fear memory, suggesting an important role of the processing of proBDNF in learning processes (Barnes and Thomas 2008). It seems possible that in $\mathrm{BDNF}^{+/-}$mice the relative amount of proBDNF and mature BDNF are altered. Since the ELISA kit used in the present study could not discriminate between pro- and mature BDNF, such alterations in BDNF processing were not detectable in our experiments. In future studies it should be very interesting to analyze whether differences in BDNF processing can in fact account for the observed age-dependent learning deficit.

Interestingly, in our experiments fear learning could be restored in older animals by applying a stronger conditioning protocol, i.e., increased number of CS-US-pairings (cf. Fig. 3C). This indicates that fear learning in adult $\mathrm{BDNF}^{+/-}$mice is only impaired, but not completely abolished. Furthermore, this rescue experiment also excludes that the observed learning deficit is due to alterations in sensory systems, like an acceleration of the hearing loss that is described for C57BL/6 mice, starting at $\sim 3$ mo of age (Mikaelian et al. 1974). A similar rescue effect of an increasing number of CS-US pairings was also reported for TrkB-signalingdeficient mice (Musumeci et al. 2009). This rescue phenomenon of stronger conditioning protocols might be explained by compensatory activation of other than the BDNF/TrkB signaling pathway. Alternatively, more repetitions of the CS-US association might lead to an increased secretion of the remaining BDNF in $\mathrm{BDNF}^{+/-}$animals, which then crosses a critical threshold of $\mathrm{BDNF} / \mathrm{TrkB}$ signaling to support/induce the formation of fear memory.

In contrast, when we applied a weaker fear-conditioning procedure (i.e., one CS-US pairing) to 2-mo-old $\mathrm{BDNF}^{+/-}$mice, these mice still showed intact fear learning, comparable to wildtype littermates. This rules out that the observed learning deficit in $\mathrm{BDNF}^{+/-}$mice depends only on the number of CS-US pairings. Rather, it seems to depend on the intensity of the fear-conditioning procedure in general, as well as on the age of the tested animals, further stressing the hypothesis that around 3 mo of age a mechanistic change in fear learning takes place in the mice (see discussion above).

In general it seems like $\mathrm{BDNF}^{+/-}$mice express an increased baseline anxiety throughout fear memory retrieval. However, this difference between $\mathrm{WT}$ and $\mathrm{BDNF}^{+/-}$mice did not reach significance for any age group and, in addition, the values of freezing expressed during the pre-CS remained in a similar range throughout all tested ages. Also, a ceiling effect can be excluded since (1) young $\mathrm{BDNF}^{+-}$and WT animals are able to express increased freezing in response to the CS and (2) 6-mo-old $\mathrm{BDNF}^{+/-}$mice are also able to express increased freezing behavior $(\sim 65 \%)$ in response to the CS if a stronger conditioning protocol is applied (cf. Fig. 3C). Thus, the observed learning deficit could not be attributed to a generalized fear in older $\mathrm{BDNF}^{+/-}$mice.

As $\mathrm{BDNF}^{+/-}$mice have been reported to show a more pronounced increase in bodyweight with age than wild-type littermates (Lyons et al. 1999; Kernie et al. 2000; Boger et al. 2011), we tested the agility of the animals in the open-field paradigm. Although we observed the same changes in body weight, as reported by the above-mentioned studies, the increased body weight in the adult $\mathrm{BDNF}^{+/-}$mice did not affect their spontaneous motor activity. This is in line with several previous studies analyzing motor activity in $\mathrm{BDNF}^{+/-}$mice using the open-field paradigm (Lyons et al. 1999; MacQueen et al. 2001; Chourbaji et al. 2004), although some other studies observed a hyperactive behavior of $\mathrm{BDNF}^{+/-}$mice (Kernie et al. 2000; Zhu et al. 2009). Heterogenous results regarding the activity level have also been described in studies using different forebrain-restricted inducible $\mathrm{BDNF}^{-/-}$mice, reporting either hyperactive behavior (Autry et al. 2009), hypoactive behavior (Gorski et al. 2003), or no such alterations (Ito et al. 2011) in the open-field task. Thus, the exact impact of reduced BDNF-levels on the spontaneous motor activity still remains unclear. Importantly, animals tested in our study did not show any hyper- or hypoactive behavior, thus ruling out that an altered activity pattern might interfere with the expression of freezing behavior.

We also tested the anxiety behavior of the animals and observed no differences between the two genotypes either in the elevated plus maze test or in any anxiety-related behavior in the open-field test, confirming observations of other studies using $\mathrm{BDNF}^{+/-}$mice or inducible forebrain-restricted $\mathrm{BDNF}^{-/-}$ mice (Montkowski and Holsboer 1997; MacQueen et al. 2001; Gorski et al. 2003; Chourbaji et al. 2004; Ren-Patterson et al. 2005; Autry et al. 2009; Sakata et al. 2010; Ito et al. 2011). These results rule out that an altered anxiety level of the $\mathrm{BDNF}^{+/-}$mice might be responsible for the observed learning deficit. It should be noted that previous testing in the open-field or hole board test could affect anxiety levels measured in a subsequent elevated plus maze test (e.g., Rodgers and Cole 1993; File 2001), but since we observed very similar behavior in both genotypes in both tests we do not believe that this order of behavioral tests was a confounding factor for the results in the present study.

In conclusion, our study reveals an age-dependent learning deficit in amygdala-dependent fear learning in $\mathrm{BDNF}^{+/-}$mice when the animals are 3 mo of age or older. Furthermore, we demonstrate that there is a positive correlation between the BDNF protein level in the basolateral amygdala and the individual fear-learning performance, further stressing the importance of BDNF in the generation of amygdala-dependent fear memories. However, we did not observe any age-dependent changes in $\mathrm{BDNF}$ protein levels in the amygdala of $\mathrm{BDNF}^{+/-}$mice. This suggests either a reduced transactivation of TrkB in aged animals or reduced signaling by additional ligand/receptor pathways that co-regulate fear learning during the aging process in $\mathrm{BDNF}^{+/-}$ mice. 


\section{Materials and Methods}

\section{Animals}

Heterozygous BDNF knock-out mice (Korte et al. 1995) were crossed with C57BL/6J wild-type mice (Jax-Mice, Charles River, Sulzfeld, Germany) for more than 15 generations. The offspring of these animals were weaned at postnatal days $25-28$. The animals were kept in groups of three to four animals per cage, had free access to food and water, and were maintained at a $12-12 \mathrm{~h}$ light-dark-cycle (lights on at 7:00 a.m.). All behavioral experiments were carried out during the light phase of the animals. For the experiments, only male mice between 1 and 6 mo of age were used. For each age group, separate sets of 8-12 animals per genotype were used. All experiments were performed in accordance to the ethical guidelines for the use of animals in experiments and were approved by the local animal care committee (Landesverwaltungsamt Sachsen-Anhalt, IPHY-G-02-897/08).

\section{Open field}

As an open field we used a cubic arena $\left(50 \times 50 \times 50 \mathrm{~cm}^{3}\right)$ made of light-gray metal. The animals were randomly placed in one of the four corners of the arena and could freely explore the whole arena for $10 \mathrm{~min}$. All behaviors were recorded by a video camera from above and were quantified by using automated tracking software (Any-maze, Stoelting Co.). A square of $25 \times 25 \mathrm{~cm}^{2}$ in the middle of the arena was defined as the center area. To quantify the spontaneous motor activity of the animals we analyzed the traveled distance and the average speed of the animals. Also, to assess the baseline anxiety levels of the animals, we quantified the time the animals spent in the center of the arena as well as the number of entries into the center area. After each test, the arena was thoroughly cleaned with $70 \%$ ethanol.

\section{Elevated plus maze}

The elevated plus maze was made from opaque PVC and consisted of four arms $\left(30 \times 6 \mathrm{~cm}^{2}\right)$ that were elevated $40 \mathrm{~cm}$ above the table surface. Two of the four arms were surrounded by $14.5-\mathrm{cm}$-high walls (closed arms). The intersection of the arms was defined as center area $\left(6 \times 6 \mathrm{~cm}^{2}\right)$. At the beginning of each test, the animals were placed in the center of the maze, randomly facing either toward an open or a closed arm. The animals were videotaped from above and most of the behaviors were quantified by the Any-maze software. Head dips and risk assessment behavior were quantified by a human observer. As risk assessment we defined a stretched attend position of the animal from the closed toward the open arm. Head dips were scored when at least the entire head was beyond the open arms. The human observer was blind to the genotype of the tested animals. In addition, some of the video files were reanalyzed by a second observer who was also not aware of the condition of the animals. A statistical analysis revealed a high correlation between both observers $(r=0.89)$. After each test the apparatus was thoroughly cleaned with $70 \%$ ethanol.

\section{Fear conditioning}

For the fear-conditioning experiments we used a fear-conditioning device from TSE Systems (Bad Homburg). The fear-conditioning chamber consisted of a quadratic box $\left(23 \times 23 \mathrm{~cm}^{2}\right)$ that was located in a sound-attenuating chamber. On the ceiling of this chamber was a loudspeaker to present the conditioned stimuli and a light source to illuminate the chamber. The floor of the test box consisted of a grid floor in order to deliver the electric foot shock to the animals. Around the test box was a frame of infrared light beams to analyze the activity of the animals. In order to change the contextual settings between fear conditioning and fear memory retrieval experiments, the walls of the test box were made of either black or transparent Plexiglas. Furthermore, we randomly cleaned the boxes either with $70 \%$ alcohol or with Decosept AF (Dr. Schumacher GmbH), in order to provide two different contextual odor stimuli.
As a conditioned stimulus (CS) we used an $8-\mathrm{kHz}$ sine tone with an intensity of $70 \mathrm{~dB}$ SPL lasting $30 \mathrm{sec}$. The CS was paired three times with a coterminating scrambled foot shock (US, $0.7 \mathrm{~mA}, 1 \mathrm{sec})$. One day later, the fear memory of these animals was assessed by exposing them five times to the CS (30 sec) after a 240-sec habituation period. The fear memory test was performed in an opposed context compared with the fear-conditioning training.

To test the short-term memory of the animals, we performed the same experimental procedure as mentioned above, but shortened the time between conditioning and retrieval to $20 \mathrm{~min}$.

Before the experiments started, we compared the automatized freezing detection with those of a human observer and adjusted the detection threshold in the FCS software such that a good correlation between hand-scoring and automated freezing detection was assured $(r=0.84)$.

\section{BDNF-protein quantification}

After finishing all behavioral testing the animals were anesthetized with Isofluran (Baxter) and decapitated. The brains were removed and sliced using an ice-cold brain matrix (AgnTho's AB). Then the basolateral amygdalae were punched out using a softtissue biopsy puncher (Zivic instruments), weighed, and immediately shock-frozen in liquid nitrogen and stored at $-80^{\circ} \mathrm{C}$.

For BDNF-protein quantification we used the BDNF Quantikine ELISA kit (R\&D Systems). The tissue samples were processed according to the kit instructions.

\section{Statistics}

All data were analyzed by using analysis of variance (ANOVA) tests, followed by post-hoc Tukey comparisons. All calculations were performed by using JMP (SAS Institute Inc., Version 8) software.

\section{Acknowledgments}

We thank Tanja Brigadski for her support in establishing the ELISA measurements and Anne Petzold for her assistance in analyzing some of the data. Furthermore, we thank Colette Obst, Sybille Natho, Margit Schmidt, and Evelyn Friedl for excellent technical assistance.

This work was supported by the DFG, SFB779/B6.

\section{References}

Abidin I, Kohler T, Weiler E, Zoidl G, Eysel UT, Lessmann V, Mittmann T. 2006. Reduced presynaptic efficiency of excitatory synaptic transmission impairs LTP in the visual cortex of BDNF-heterozygous mice. Eur J Neurosci 24: 3519-3531.

Andero R, Heldt SA, Ye K, Liu X, Armario A, Ressler KJ. 2010. Effect of 7,8-Dihydroxyflavone, a small-molecule TrkB agonist, on emotional learning. Am J Psychiatry 168: 163-172.

Autry AE, Adachi M, Cheng P, Monteggia LM. 2009. Gender-specific impact of brain-derived neurotrophic factor signaling on stress-induced depression-like behavior. Biol Psychiatry 66: 84-90.

Barichello T, Belarmino E Jr, Comim CM, Cipriano AL, Generoso JS, Savi GD, Stertz L, Kapczinski F, Quevedo J. 2010. Correlation between behavioral deficits and decreased brain-derived neurotrophic [correction of neurotrofic] factor in neonatal meningitis. J Neuroimmunol 223: 73-76.

Barnes P, Thomas KL. 2008. Proteolysis of proBDNF is a key regulator in the formation of memory. PLoS One 3: e3248. doi: 10.1371/ jornal.pone.0003248.

Bekinschtein P, Cammarota M, Izquierdo I, Medina JH. 2008. BDNF and memory formation and storage. Neuroscientist 14: 147-156.

Boger HA, Mannangatti P, Samuvel DJ, Saylor AJ, Bender TS, McGinty JF, Fortress AM, Zaman V, Huang P, Middaugh LD, et al. 2011. Effects of brain-derived neurotrophic factor on dopaminergic function and motor behavior during aging. Genes Brain Behav 10: 186-198.

Chen ZY, Jing D, Bath KG, Ieraci A, Khan T, Siao CJ, Herrera DG, Toth M, Yang C, McEwen BS, et al. 2006. Genetic variant BDNF (Val66Met) polymorphism alters anxiety-related behavior. Science 314: $140-143$. 
Chourbaji S, Hellweg R, Brandis D, Zorner B, Zacher C, Lang UE, Henn FA, Hortnagl H, Gass P. 2004. Mice with reduced brain-derived neurotrophic factor expression show decreased choline acetyltransferase activity, but regular brain monoamine levels and unaltered emotional behavior. Brain Res Mol Brain Res 121: 28-36.

Ciocchi S, Herry C, Grenier F, Wolff SB, Letzkus JJ, Vlachos I, Ehrlich I, Sprengel R, Deisseroth K, Stadler MB, et al. 2010. Encoding of conditioned fear in central amygdala inhibitory circuits. Nature 468: $277-282$.

Cowansage KK, Ledoux JE, Monfils MH. 2010. Brain-derived neurotrophic factor: A dynamic gatekeeper of neural plasticity. Curr Mol Pharmacol 3: $12-29$.

Croll SD, Ip NY, Lindsay RM, Wiegand SJ. 1998. Expression of BDNF and trkB as a function of age and cognitive performance. Brain Res 812: 200-208.

Cunningham MG, Bhattacharyya S, Benes FM. 2002. Amygdalo-cortical sprouting continues into early adulthood: Implications for the development of normal and abnormal function during adolescence. J Comp Neurol 453: 116-130.

Cunningham MG, Bhattacharyya S, Benes FM. 2008. Increasing Interaction of amygdalar afferents with GABAergic interneurons between birth and adulthood. Cereb Cortex 18: 1529-1535.

Egan MF, Kojima M, Callicott JH, Goldberg TE, Kolachana BS, Bertolino A, Zaitsev E, Gold B, Goldman D, Dean M, et al. 2003. The BDNF val66met polymorphism affects activity-dependent secretion of BDNF and human memory and hippocampal function. Cell 112: 257-269.

Ehrlich I, Humeau Y, Grenier F, Ciocchi S, Herry C, Luthi A. 2009. Amygdala inhibitory circuits and the control of fear memory. Neuron 62: 757-771.

Erickson KI, Miller DL, Roecklein KA. 2011. The aging hippocampus: Interactions between exercise, depression, and BDNF. Neuroscientist 18: $82-97$.

Ernfors P, Lee KF, Jaenisch R. 1994. Mice lacking brain-derived neurotrophic factor develop with sensory deficits. Nature 368 : 147-150.

Fendt M, Fanselow MS. 1999. The neuroanatomical and neurochemical basis of conditioned fear. Neurosci Biobehav Rev 23: 743-760.

File SE. 2001. Factors controlling measures of anxiety and responses to novelty in the mouse. Behav Brain Res 125: 151-157.

Francia N, Cirulli F, Chiarotti F, Antonelli A, Aloe L, Alleva E. 2006. Spatial memory deficits in middle-aged mice correlate with lower exploratory activity and a subordinate status: Role of hippocampal neurotrophins. Eur J Neurosci 23: 711-728.

Genoud C, Knott GW, Sakata K, Lu B, Welker E. 2004. Altered synapse formation in the adult somatosensory cortex of brain-derived neurotrophic factor heterozygote mice. J Neurosci 24: 2394-2400.

Gorski JA, Balogh SA, Wehner JM, Jones KR. 2003. Learning deficits in forebrain-restricted brain-derived neurotrophic factor mutant mice. Neuroscience 121: 341-354.

Gottmann K, Mittmann T, Lessmann V. 2009. BDNF signaling in the formation, maturation and plasticity of glutamatergic and GABAergic synapses. Exp Brain Res 199: 203-234.

Hefner K, Holmes A. 2007. Ontogeny of fear-, anxiety- and depression-related behavior across adolescence in C57BL/6J mice. Behav Brain Res 176: 210-215.

Hill RA, van den Buuse M. 2011. Sex-dependent and region-specific changes in TrkB signaling in BDNF heterozygous mice. Brain Res 1384: $51-60$

Hopkins ME, Bucci DJ. 2010. BDNF expression in perirhinal cortex is associated with exercise-induced improvement in object recognition memory. Neurobiol Learn Mem 94: 278-284.

Hwang JJ, Park MH, Choi SY, Koh JY. 2005. Activation of the Trk signaling pathway by extracellular zinc. Role of metalloproteinases. J Biol Chem 280: $11995-12001$.

Hwang JJ, Park MH, Koh JY. 2007. Copper activates TrkB in cortical neurons in a metalloproteinase-dependent manner. J Neurosci Res 85: $2160-2166$

Ito W, Pan BX, Yang C, Thakur S, Morozov A. 2009. Enhanced generalization of auditory conditioned fear in juvenile mice. Learn Mem 16: 187-192.

Ito W, Chehab M, Thakur S, Li J, Morozov A. 2011. BDNF-restricted knockout mice as an animal model for aggression. Genes Brain Behav 10: $365-374$

Johansen JP, Cain CK, Ostroff LE, Ledoux JE. 2011. Molecular mechanisms of fear learning and memory. Cell 147: 509-524.

Jones SV, Stanek-Rattiner L, Davis M, Ressler KJ. 2007. Differential regional expression of brain-derived neurotrophic factor following olfactory fear learning. Learn Mem 14: 816-820.

Jovanovic T, Ressler KJ. 2010. How the neurocircuitry and genetics of fear inhibition may inform our understanding of PTSD. Am J Psychiatry 167: $648-662$.
Karege F, Schwald M, Cisse M. 2002. Postnatal developmental profile of brain-derived neurotrophic factor in rat brain and platelets. Neurosci Lett 328: 261-264.

Karpova NN, Pickenhagen A, Lindholm J, Tiraboschi E, Kulesskaya N, Agustsdottir A, Antila H, Popova D, Akamine Y, Bahi A, et al. 2011. Fear erasure in mice requires synergy between antidepressant drugs and extinction training. Science 334: 1731-1734.

Katoh-Semba R, Semba R, Takeuchi IK, Kato K. 1998. Age-related changes in levels of brain-derived neurotrophic factor in selected brain regions of rats, normal mice and senescence-accelerated mice: A comparison to those of nerve growth factor and neurotrophin-3. Neurosci Res 31: $227-234$.

Kernie SG, Liebl DJ, Parada LF. 2000. BDNF regulates eating behavior and locomotor activity in mice. EMBO J 19: 1290-1300.

Koenigs M, Grafman J. 2009. Posttraumatic stress disorder: The role of medial prefrontal cortex and amygdala. Neuroscientist 15: $540-548$.

Kolbeck R, Bartke I, Eberle W, Barde YA. 1999. Brain-derived neurotrophic factor levels in the nervous system of wild-type and neurotrophin gene mutant mice. J Neurochem 72: 1930-1938.

Korte M, Carroll P, Wolf E, Brem G, Thoenen H, Bonhoeffer T. 1995. Hippocampal long-term potentiation is impaired in mice lacking brain-derived neurotrophic factor. Proc Natl Acad Sci 92: 8856-8860.

LeDoux J. 2000. Emotion circuits in the brain. Annu Rev Neurosci 23: $155-184$

LeDoux J. 2007. The amygdala. Curr Biol 17: R868-R874.

Lessmann V, Gottmann K, Malcangio M. 2003. Neurotrophin secretion: Current facts and future prospects. Prog Neurobiol 69: 341-374.

Liu IY, Lyons WE, Mamounas LA, Thompson RF. 2004. Brain-derived neurotrophic factor plays a critical role in contextual fear conditioning. J Neurosci 24: 7958-7963.

Lyons WE, Mamounas LA, Ricaurte GA, Coppola V, Reid SW, Bora SH, Wihler C, Koliatsos VE, Tessarollo L. 1999. Brain-derived neurotrophic factor-deficient mice develop aggressiveness and hyperphagia in conjunction with brain serotonergic abnormalities. Proc Natl Acad Sci 96: $15239-15244$

MacQueen GM, Ramakrishnan K, Croll SD, Siuciak JA, Yu G, Young LT, Fahnestock M. 2001. Performance of heterozygous brain-derived neurotrophic factor knockout mice on behavioral analogues of anxiety, nociception, and depression. Behav Neurosci 115: $1145-1153$.

Mahan AL, Ressler KJ. 2012. Fear conditioning, synaptic plasticity and the amygdala: Implications for posttraumatic stress disorder. Trends Neurosci 35: 24-35.

Maren S. 2001. Neurobiology of Pavlovian fear conditioning. Annu Rev Neurosci 24: 897-931.

McKernan MG, Shinnick-Gallagher P. 1997. Fear conditioning induces a lasting potentiation of synaptic currents in vitro. Nature 390: 607-611.

Meis S, Endres T, Lessmann V. 2012. Postsynaptic BDNF signalling regulates long-term potentiation at thalamo-amygdala afferents. J Physiol 590: 193-208.

Mikaelian DO, Warfield D, Norris O. 1974. Genetic progressive hearing loss in the C57-b16 mouse. Relation of behavioral responses to chochlear anatomy. Acta Otolaryngol 77: 327-334.

Monteggia LM, Barrot M, Powell CM, Berton O, Galanis V, Gemelli T, Meuth S, Nagy A, Greene RW, Nestler EJ. 2004. Essential role of brain-derived neurotrophic factor in adult hippocampal function. Proc Natl Acad Sci 101: 10827-10832.

Monteggia LM, Luikart B, Barrot M, Theobold D, Malkovska I, Nef S, Parada LF, Nestler EJ. 2007. Brain-derived neurotrophic factor conditional knockouts show gender differences in depression-related behaviors. Biol Psychiatry 61: 187-197.

Montkowski A, Holsboer F. 1997. Intact spatial learning and memory in transgenic mice with reduced BDNF. Neuroreport 8: 779-782.

Musumeci G, Sciarretta C, Rodriguez-Moreno A, Al BM, Negrete-Diaz V, Costanzi M, Berno V, Egorov AV, von Bohlen Und HO, Cestari V, et al. 2009. TrkB modulates fear learning and amygdalar synaptic plasticity by specific docking sites. J Neurosci 29: 10131-10143.

Ou LC, Gean PW. 2006. Regulation of amygdala-dependent learning by brain-derived neurotrophic factor is mediated by extracellular signal-regulated kinase and phosphatidylinositol-3-kinase. Neuropsychopharmacology 31: 287-296.

Ou LC, Yeh SH, Gean PW. 2010. Late expression of brain-derived neurotrophic factor in the amygdala is required for persistence of fear memory. Neurobiol Learn Mem 93: 372-382.

Pan BX, Ito W, Morozov A. 2009. Divergence between thalamic and cortical inputs to lateral amygdala during juvenile-adult transition in mice. Biol Psychiatry 66: $964-971$.

Papaleo F, Silverman JL, Aney J, Tian Q, Barkan CL, Chadman KK, Crawley JN. 2011. Working memory deficits, increased anxiety-like 
traits, and seizure susceptibility in BDNF overexpressing mice. Learn Mem 18: 534-544.

Pape HC, Pare D. 2010. Plastic synaptic networks of the amygdala for the acquisition, expression, and extinction of conditioned fear. Physiol Rev 90: $419-463$.

Rattiner LM, Davis M, French CT, Ressler KJ. 2004a. Brain-derived neurotrophic factor and tyrosine kinase receptor B involvement in amygdala-dependent fear conditioning. J Neurosci 24: 4796-4806.

Rattiner LM, Davis M, Ressler KJ. 2004b. Differential regulation of brain-derived neurotrophic factor transcripts during the consolidation of fear learning. Learn Mem 11: 727-731.

Rattiner LM, Davis M, Ressler KJ. 2005. Brain-derived neurotrophic factor in amygdala-dependent learning. Neuroscientist 11: 323-333.

Ren-Patterson RF, Cochran LW, Holmes A, Sherrill S, Huang SJ, Tolliver T, Lesch KP, Lu B, Murphy DL. 2005. Loss of brain-derived neurotrophic factor gene allele exacerbates brain monoamine deficiencies and increases stress abnormalities of serotonin transporter knockout mice. J Neurosci Res 79: 756-771.

Ren-Patterson RF, Cochran LW, Holmes A, Lesch KP, Lu B, Murphy DL. 2006. Gender-dependent modulation of brain monoamines and anxiety-like behaviors in mice with genetic serotonin transporter and BDNF deficiencies. Cell Mol Neurobiol 26: 755-780.

Rodgers RJ, Cole JC. 1993. Influence of social isolation, gender, strain, and prior novelty on plus-maze behaviour in mice. Physiol Behav 54: $729-736$.

Rogan MT, Staubli UV, LeDoux J. 1997. Fear conditioning induces associative long-term potentiation in the amygdala. Nature 390: 604-607.

Sakata K, Jin L, Jha S. 2010. Lack of promoter IV-driven BDNF transcription results in depression-like behavior. Genes Brain Behav 9: 712-721.

Silhol M, Bonnichon V, Rage F, Tapia-Arancibia L. 2005. Age-related changes in brain-derived neurotrophic factor and tyrosine kinase receptor isoforms in the hippocampus and hypothalamus in male rats. Neuroscience 132: 613-624.

Soliman F, Glatt CE, Bath KG, Levita L, Jones RM, Pattwell SS, Jing D, Tottenham N, Amso D, Somerville LH, et al. 2010. A genetic variant BDNF polymorphism alters extinction learning in both mouse and human. Science 327: 863-866.

Swift JL, Godin AG, Dore K, Freland L, Bouchard N, Nimmo C, Sergeev M, De KY, Wiseman PW, Beaulieu JM. 2011. Quantification of receptor tyrosine kinase transactivation through direct dimerization and surface density measurements in single cells. Proc Natl Acad Sci 108: 7016-7021.

Tebano MT, Martire A, Chiodi V, Ferrante A, Popoli P. 2010. Role of adenosine $\mathrm{A}(2 \mathrm{~A})$ receptors in modulating synaptic functions and brain levels of BDNF: A possible key mechanism in the pathophysiology of Huntington's disease. ScientificWorldJournal 10: $1768-1782$.

von Bohlen und Halbach O. 2010. Involvement of BDNF in age-dependent alterations in the hippocampus. Front Aging Neurosci 2. doi: 10.2289/ fnagi.2010.00036.

Wu YC, Hill RA, Klug M, van den BM. 2012. Sex-specific and region-specific changes in BDNF-TrkB signalling in the hippocampus of 5-HT1A receptor and BDNF single and double mutant mice. Brain Res 1452: $10-17$.

Yoshii A, Constantine-Paton M. 2010. Postsynaptic BDNF-TrkB signaling in synapse maturation, plasticity, and disease. Dev Neurobiol 70: 304-322.

Zhu SW, Codita A, Bogdanovic N, Hjerling-Leffler J, Ernfors P, Winblad B, Dickins DW, Mohammed AH. 2009. Influence of environmental manipulation on exploratory behaviour in male BDNF knockout mice. Behav Brain Res 197: 339-346.

Received August 6, 2012; accepted in revised form August 24, 2012. 


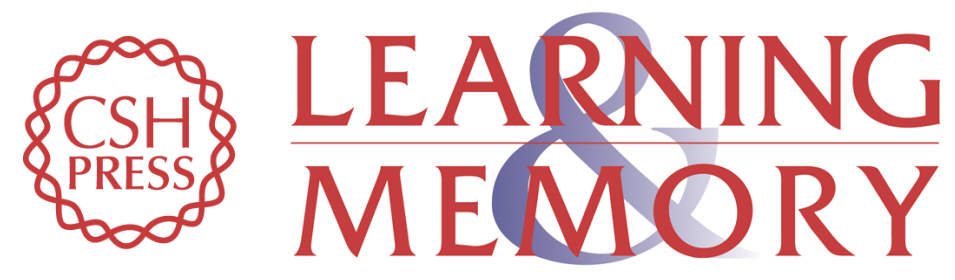

\section{Age-dependent deficits in fear learning in heterozygous BDNF knock-out mice}

Thomas Endres and Volkmar Lessmann

Learn. Mem. 2012, 19:

Access the most recent version at doi:10.1101/lm.028068.112

References This article cites 77 articles, 17 of which can be accessed free at:

http://learnmem.cshlp.org/content/19/12/561.full.html\#ref-list-1

License

Email Alerting Receive free email alerts when new articles cite this article - sign up in the box at the Service top right corner of the article or click here. 